\title{
A COMPARATIVE STUDY OF ISOBARIC 0.5\% LEVOBUPIVACAINE COMBINED WITH 50 MCG FENTANYL VERSUS ISOBARIC 0.5\% ROPIVACAINE COMBINED WITH 50 MCG FENTANYL IN LUMBAR EPIDURAL ANAESTHESIA FOR ELECTIVE INFRAUMBILICAL SURGERY
}

\author{
Swarnali Dasgupta1, Samarendra Nath Samui², Sarbari Swaika³, Arpita Choudhary ${ }^{4}$ \\ ${ }_{1}^{1}$ Resident, Department of Anaesthesiology, IPGME \& R, Kolkata. \\ ${ }^{2}$ Assistant Professor, Department of Anaesthesiology, IPGME \& R, Kolkata. \\ ${ }^{3}$ Associate Professor, Department of Anaesthesiology, IPGME \& R, Kolkata. \\ ${ }^{4}$ Resident, Department of Anaesthesiology, IPGME \& R, Kolkata.
}

\begin{tabular}{l}
\hline ABSTRACT \\
\hline BACKGROUND \\
This prospective, randomised, double-blinded study compared the onset and duration of epidural anaesthesia produced by \\
levobupivacaine and ropivacaine.
\end{tabular}

\section{MATERIALS AND METHODS}

Seventy adult patients of ASA physical status I and II were divided into two groups of 35 each by pre-decided randomisation schedule, Group R to receive epidural isobaric ropivacaine $0.5 \% 15 \mathrm{~mL}$ combined with $50 \mathrm{mcg}$ fentanyl and Group L to receive epidural isobaric levobupivacaine $0.5 \% 15 \mathrm{~mL}$ combined with $50 \mathrm{mcg}$ fentanyl. A blinded observer evaluated onset and regression of motor and sensory block, and requirement of rescue analgesia.

\section{RESULTS}

Onset of sensory block was comparable in both groups. Onset of motor block was longer in group R (18.4+/- 1.77 min. in Group R vs. $15.69+/-0.76$ min. in group L). In both groups, maximum sensory level reached was T5. Duration of motor block was found to be significantly shorter in group R as compared to group L (175.9+/- $8.53 \mathrm{~min}$. in Group L vs. 150.9+/- 7.12 min. in Group R). Duration of analgesia was comparable in both groups (231.0+/- 9.2195 min. in Group L and 233.54 +/- 8.4064 min. in Group R). Haemodynamic variables were comparable in both groups.

\section{CONCLUSIONS}

Levobupivacaine $0.5 \%$ produced a sensory block of similar onset, quality, and duration as ropivacaine $0.5 \%$ but a longer duration of motor block.

\section{KEYWORDS}

Levobupivacaine, Ropivacaine, Lumber Epidural Anaesthesia, Infraumbilical Surgery.

HOW TO CITE THIS ARTICLE: Dasgupta S, Samui SN, Swaika S, et al. A comparative study of isobaric $0.5 \%$ levobupivacaine combined with $50 \mathrm{mcg}$ fentanyl versus isobaric $0.5 \%$ ropivacaine combined with $50 \mathrm{mcg}$ fentanyl in lumbar epidural anaesthesia for elective infraumbilical surgery. J. Evolution Med. Dent. Sci. 2016;5(95):7029-7033, DOI: 10.14260/Jemds/2016/1590

\section{BACKGROUND}

As perioperative physicians, anaesthesiologists are responsible for proper pain management during the perioperative period, creation of innovative approaches to acute pain management, and extending their care for acute postoperative pain services as well.

A variety of neuraxial and peripheral regional analgesic techniques are being used for effective perioperative analgesia. In general, the analgesia provided by epidural and peripheral techniques is superior to that with only systemic opioids, ${ }^{1}$ with reduced morbidity and mortality. ${ }^{2,3}$ Regional anaesthesia offers several advantages over general anaesthesia - provides excellent intraoperative analgesia, blunts stress response to surgery, decreases intraoperative

Financial or Other, Competing Interest: None.

Submission 22-10-2016, Peer Review 13-11-2016,

Acceptance 21-11-2016, Published 28-11-2016.

Corresponding Author:

Dr. Sarbari Swaika,

Associate Professor,

Department of Anaesthesiology,

IPGME \& R. Kolkata.

E-mail:dr.s.swaika@gmail.com

DOI: $10.14260 /$ jemds $/ 2016 / 1590$ blood loss, lowers the incidence of postoperative thromboembolic events and provides analgesia in early postoperative period.

Epidural anaesthesia is a versatile technique widely used for infraumbilical surgeries. The main advantages of epidural anaesthesia are the level of block and duration of analgesia may be controlled by the anaesthesiologist. The recognition of acute life-threatening cardiotoxicity of bupivacaine 4,5 led to the search for a local anaesthetic agent comparable with bupivacaine but with lower cardiotoxicity. This resulted in the development of a relatively new amide, ropivacaine, registered for use in $1996^{4}$ but introduced in India only in 2009.

Ropivacaine is produced as pure 'S' enantiomer with lower lipid solubility, easier reversibility after inadvertent intravascular injection, significant reduction in central nervous system toxicity, lesser motor block and greater differentiation of sensory and motor block. ${ }^{6}$ In equal concentrations, ropivacaine and bupivacaine produced similar sensory and motor block after epidural administration with slightly longer block duration with bupivacaine. ${ }^{7}$ Increasing concentrations caused quicker onset, greater intensity, slower regression, and longer duration of motor blockade. ${ }^{8}$ Motor 
blockade of $0.75 \%$ ropivacaine was comparable to $0.5 \%$ bupivacaine. $^{9}$

Levobupivacaine hydrochloride is the levo stereoisomer form of the racemic form of bupivacaine hydrochloride. Levobupivacaine has demonstrated anaesthetic potency similar to bupivacaine, superior pharmacokinetic profile, lesser cardiovascular and central nervous system toxicity than bupivacaine and better perioperative haemodynamic stability. ${ }^{10}$ Some studies have shown that, depending on the dose used, levobupivacaine may produce a significantly longer duration of sensory block than bupivacaine. ${ }^{11}$ On the other hand, some studies showed that levobupivacaine produced same duration of sensory block but less amount of motor block than bupivacaine. ${ }^{12}$

Levobupivacaine and ropivacaine cause less residual motor blockade compared to bupivacaine. Hence, considering the advent of new drug levobupivacaine in Indian market we proposed to compare levobupivacaine with ropivacaine.

The purpose of this study was to evaluate the duration of analgesia and motor blockade, perioperative haemodynamic effects and side effect profiles of equal dose of isobaric levobupivacaine $0.5 \%$ and fentanyl combination versus isobaric ropivacaine $0.5 \%$ and fentanyl combination in adult patients undergoing elective infraumbilical surgery under epidural anaesthesia.

\section{MATERIALS AND METHODS}

A randomised prospective clinical study of patients undergoing elective infraumbilical abdominal surgeries receiving either epidural ropivacaine or levobupivacaine was undertaken after obtaining written informed consent from the patients and institutional ethics committee approval. For the purpose of sample size calculation, the difference in duration of analgesia was taken as the primary outcome measure. It was calculated that 35 subjects would be required per group in order to detect a difference of $30 \mathrm{~min}$. with $80 \%$ study power and $5 \%$ probability of Type-I error. The calculation assumed a standard deviation of $45 \mathrm{~min}$. for the duration of sensory block. Sample size calculation was done by n.master-2.0 (Department of Biostatistics, Christian Medical College, Vellore; 2012) software.

Seventy patients were divided into two groups of 35 each by pre-decided randomisation schedule, Group $\mathrm{R}$ to receive epidural isobaric ropivacaine $0.5 \% 15 \mathrm{~mL}$ combined with 50 mcg fentanyl and Group L to receive epidural isobaric levobupivacaine $0.5 \% 15 \mathrm{~mL}$ combined with $50 \mathrm{mcg}$ fentanyl. Adult patients aged between 19 and 60 years age and BMI 18.5 to $29.9 \mathrm{~kg} /$ meter $^{2}$ of both sexes of American Society of Anaesthesiologists (ASA) physical status Grade I and II were included in the study.

Exclusion criteria included patient refusal, infection at the site of injection, coagulopathy, neurological disorders and psychiatric disorder, heart diseases, haemodynamically compromised patients, sepsis, gross anatomical abnormality of vertebral column and known allergy to the study drugs.

After preanaesthetic checkup, patients were given tablet 10 $\mathrm{mg}$ oral diazepam and tablet ranitidine $150 \mathrm{mg}$ night before operation and kept 8 hours fasting before surgery.

After receiving the patients in operation theatre, an intravenous line was established with an 18G cannula in a large vein of hand and 10 to $15 \mathrm{~mL} / \mathrm{kg}$ body weight lactated Ringer's solution administered over $1 \mathrm{hr}$.
The patients were monitored by NIBP, continuous ECG \& pulse oximetry. Under strict aseptic conditions, with the patient in sitting or lateral position skin and subcutaneous tissue was infiltrated with $1 \%$ lignocaine $(2 \mathrm{~mL})$ at L2-L3 or L3-L4 disc space. Epidural space was identified in the midline with an 18G Tuohy needle using loss of resistance technique with air. Epidural catheter was carefully introduced through the needle. After removal of needle $3 \mathrm{~mL}$ of lignocaine $2 \%$ with adrenaline was administered through the catheter as a test dose. After $5 \mathrm{~min}$. if there is no evidence of intravascular/intrathecal placement of catheter, $15 \mathrm{~mL}$ of test drug was injected in an incremental manner $(5 \mathrm{~mL}$ drug over 15 secs \& interval between each injection 2 min.) such that total injection time will be 4 min. 45 seconds. After completion of injection (time 0), patient was placed supine. Surgery was commenced when the sensory block reached the dermatome level T6.

Sensory blockade was assessed by pinprick using a blunt tipped needle and onset of sensory block (time from epidural injection to the time $\mathrm{T} 10$ blockade was achieved), maximum height reached were noted. It was tested every $1 \mathrm{~min}$. interval till maximum height of block reached and thereafter at $15 \mathrm{~min}$. interval intraoperatively \& postoperatively until rescue analgesia required.

Motor block was assessed using modified Bromage scale ${ }^{7}$ and graded as 0: No motor paralysis; 1 : Inability to raise extended leg; 2: Inability to flex knee; 3 : Inability to flex ankle. Time for onset of motor block (time from epidural injection to the time Bromage Grade 0 changed to Grade 1), maximum motor block and complete motor recovery noted. It was assessed every $5 \mathrm{~min}$. till onset and every $15 \mathrm{~min}$. thereafter unless restricted access during surgery prevented it.

Heart rate, mean blood pressure was recorded every 5 minutes for first $30 \mathrm{~min}$. and then at $15 \mathrm{~min}$. interval till the end of surgery and then at $30 \mathrm{~min}$. interval till rescue analgesic was required. Bradycardia, defined as heart rate (HR) $<50 / \mathrm{min}$, was managed by Inj. Atropine $0.6 \mathrm{mg}$ IV bolus (may be repeated). Hypotension, defined by decrease in mean arterial blood pressure more than $30 \%$ below baseline or in normotensive patients, fall in systolic pressure below 90 mmHg was managed by Inj. Mephentermine 3-6 mg IV bolus (titrated to patient response) along with fluid bolus (both crystalloids and colloids). We used crystalloids like Ringer's lactate, $0.9 \%$ Normal Saline as intravenous fluid. Obvious side effects like nausea and vomiting, hypotension, pruritus, retention of urine, respiratory depression were monitored.

Analgesia was assessed by VAS pain score which is a linear pain scoring tool ranging from 0 to $10 \mathrm{~cm}$ where 0 means no pain and 10 means worst possible pain. Rescue Analgesia was administered postoperatively when VAS score $>4$ or when patient requested for analgesia. Eight $\mathrm{mL}$ of $0.125 \%$ racemic bupivacaine was then administered through the epidural catheter. The duration of analgesia was assessed by time to rescue analgesia.

All raw data of study parameters were entered into a Microsoft Excel spread sheet and statistical assessment of the data was carried out using the statistical software Statistica 6.0 [Tulsa, Oklahoma: Stat Soft Inc.,2001] and GraphPad Prism version 5 [San Diego, California: GraphPad Software Inc., 2007].

Kolmogorov-Smirnoff goodness-of-fit test was applied to see whether the data distribution is normal. Results were 
summarised by descriptive statistics such as mean and standard deviation for numerical variables that are normally distributed and median and interquartile range for those that are skewed. For the variables which showed a normal distribution of intergroup comparisons, independent TwoSample T-Test was used. For the variables, which were skewed, the Mann-Whitney U test was used. Within group comparisons repeated measurements were performed with the Variance Analysis. Comparisons between two qualitative variables were performed with Pearson's Chi-Square Test and Fisher's Exact Test. p value $<0.05$ was considered to be statistically significant.

\section{RESULTS}

Demographic profiles (age, sex, body wt, BMI) and type and mean duration of surgery was comparable in both the groups. (tables 1,2)

The mean time for onset of sensory block was comparable in both groups (7.57 +/- $0.58 \mathrm{~min}$. in group L vs. 7.4+/- 0.55 min. in group R). Mean time for onset of motor block was longer in group R (18.4+/- 1.77 min. in Group R vs. 15.69 +/0.76 min. in group L) (figure 1.). Peak sensory block height attained was similar in both the groups (T5 -9, T6- 25 in levobupivacaine group and T5- 9, T6- 25 in ropivacaine group).

Modified Bromage scores in both the groups were comparable (2.9+/-0.35 in Group L vs. 2.6+/-0.84). Duration of motor block as assessed by Modified Bromage score was found to be significantly shorter in group $\mathrm{R}$ as compared to group $\mathrm{L}$ (175.9+/- 8.53 min. in Group L vs. 150.9+/- 7.12 min. in Group R) (figure 2).

The duration of analgesia was $231.0+/-9.2195 \mathrm{~min}$. and $233.54+/-8.4064$ min. in Group L and R respectively which showed no statistical significance ( $p$ value 0.2321 ).

Haemodynamic variables were comparable in both groups [Figure 3] and [Figure 4]. There was no incidence of bradycardia in both the groups. There was incidence of significant hypotension in 3 cases of group L compared to 2 in group $\mathrm{R}$ which showed no statistical difference. There were no postoperative sequelae like headache, backache, nausea and vomiting for next $24 \mathrm{~h}$. Two patients in the ropivacaine group and one patient in the levobupivacaine group were excluded from the study due to technical failure of the block.

\begin{tabular}{|c|c|c|c|}
\hline & L & R & P value \\
\hline AGE (yrs.) & 39 & 40 & 0.0632 \\
\hline SEX (M/F) & $21 / 14$ & $20 / 15$ & 1.00 \\
\hline BMI & 21.0 & 20.9 & 0.747 \\
\hline $\begin{array}{c}\text { Type of } \\
\text { Surgery }\end{array}$ & $\begin{array}{c}\text { TAH 11,VH } \\
4, \text { OCC 5, IH } \\
11, \mathrm{FH} 1\end{array}$ & $\begin{array}{c}\text { TAH 10, VH } \\
\text { 3, OCC 6, IH } \\
10, \mathrm{FH} 1\end{array}$ & 0.9946 \\
\hline $\begin{array}{c}\text { Duration of } \\
\text { Surgery } \\
\text { (min.) }\end{array}$ & 117.5 & 112.4 & 0.358 \\
\hline \multicolumn{4}{|c|}{ Table 1. Demographic Profile, } \\
Type and Duration of Surgery \\
\hline \multicolumn{4}{|c|}{} \\
\hline
\end{tabular}

Demographic profiles, type and mean duration of surgery was comparable in both the groups.

\begin{tabular}{|c|c|c|c|}
\hline $\begin{array}{c}\text { Onset SB } \\
\text { (min.) }\end{array}$ & $\begin{array}{c}7.57+/- \\
0.58\end{array}$ & $\begin{array}{c}7.4+/- \\
0.55\end{array}$ & 0.3626 \\
\hline $\begin{array}{c}\text { Onset } \\
\text { MB(min.) }\end{array}$ & $\begin{array}{c}15.69+/- \\
0.76\end{array}$ & $\begin{array}{c}18.4+/- \\
1.77\end{array}$ & 0.000 \\
\hline $\begin{array}{c}\text { Peak } \\
\text { Sensory } \\
\text { HT }\end{array}$ & $\begin{array}{c}\mathrm{T} 5-9 \\
\mathrm{~T} 6-26\end{array}$ & $\begin{array}{c}\mathrm{T} 5-9 \\
\mathrm{~T} 6-26\end{array}$ & 1.00 \\
\hline $\begin{array}{c}\text { Duration } \\
\text { MB(min.) }\end{array}$ & $\begin{array}{c}175.9+/- \\
8.53\end{array}$ & $\begin{array}{c}150.9+/- \\
7.12\end{array}$ & 0.000 \\
\hline $\begin{array}{c}\text { Duration of } \\
\text { Analgesia } \\
\text { (min.) }\end{array}$ & $\begin{array}{c}231.0+/- \\
9.219\end{array}$ & $\begin{array}{c}233.54 \\
+/- \\
8.406\end{array}$ & 0.2321 \\
\hline \multicolumn{2}{|c|}{ Table 2. Sensory and Motor Block Characteristics } \\
\hline
\end{tabular}

SB- sensory block

MB-motor block

Onset of sensory block is comparable in both groups. Onset of motor block is found to be delayed in the ropivacaine group. Duration of motor block is significantly shorter in the ropivacaine group. Duration of analgesia is similar in both the groups.

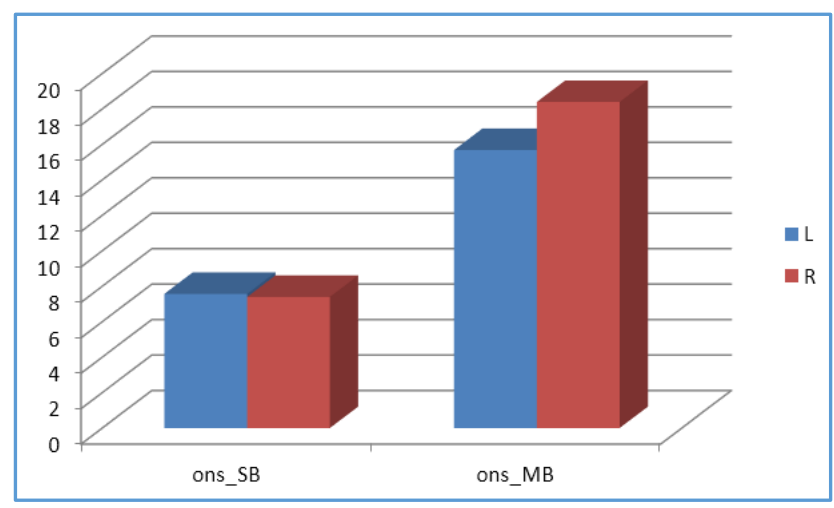

Figure 1. Onset of Sensory and Motor Block

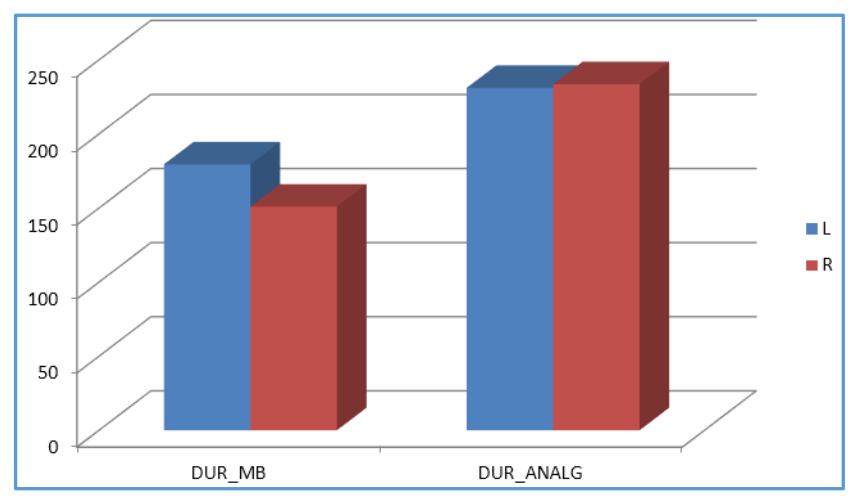

Figure 2. Duration of Motor Block and Analgesia 


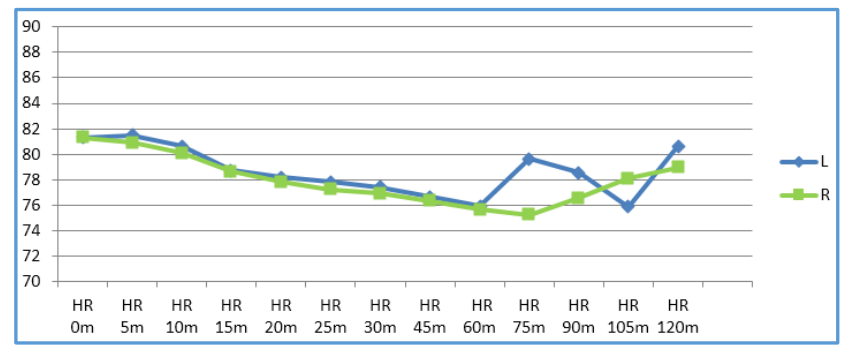

Figure 3. Comparison of Intraoperative Heart Rate (HR) between Group $L \& R$

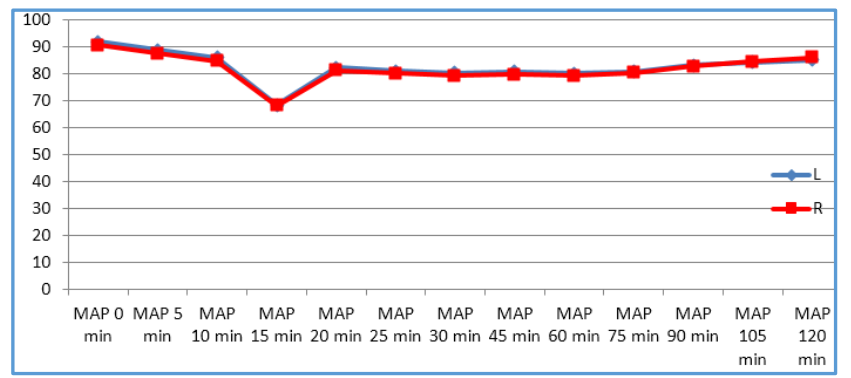

Figure 4. Comparison of Intraoperative Mean Arterial Pressure (MAP) between Group $L \& R$

\section{DISCUSSION}

Epidural anaesthesia reduces perioperative physiologic responses in addition to providing pain relief. Casati et al compared levobupivacaine $0.5 \%$ and ropivacaine $0.5 \%$ in epidural anaesthesia for major orthopaedic surgery. Sensory block regression and rescue analgesia was comparable in both the groups. ${ }^{13}$ However, $40 \%$ patients in the ropivacaine group had an intraoperative Bromage score $<2$ as compared with only $20 \%$ patients of Group levobupivacaine. Thus, the authors concluded that levobupivacaine $0.5 \%$ produces an epidural block of similar onset, quality, and duration with a motor block deeper than that produced by $0.5 \%$ ropivacaine which correlated with our study findings.

Peduto et al demonstrated that in adults undergoing lower limb surgery, levobupivacaine $0.5 \% 15 \mathrm{~mL}$ produces an epidural block with the same clinical profile as ropivacaine $0.75 \% 15 \mathrm{~mL}$. Complete resolution of motor block required $105+$ /- $63 \mathrm{~min}$. with levobupivacaine and $95+/-48 \mathrm{~min}$. with ropivacaine $(\mathrm{P}=0.86) .^{14}$

Jung et al demonstrated that levobupivacaine and ropivacaine produced equivalent efficacy and safety in epidural anaesthesia for caesarean section. ${ }^{15}$ No difference in onset time, segmental spread of sensory block and analgesic supplement between the groups. Onset time, intensity and duration of motor block were similar in both groups. Duration of motor block was $126.3+/-86.6 \mathrm{~min}$. in levobupivacaine $0.5 \%$ group vs. $106.6+/-67.6 \mathrm{~min}$. in $0.5 \%$ ropivacaine group.

Luck et al ${ }^{16}$ demonstrated that in spinal anaesthesia, patients in the ropivacaine group had more rapid recovery from motor block with a duration of 90 (60-120) min. compared to 180 (90-210) min. in levobupivacaine group ( $p$ value $<0.0001$ ) which tallied with our study.

Pablo et al found no significant differences in potencies for caudal ropivacaine and levobupivacaine. ${ }^{17}$

Chandran et al compared $0.75 \%$ ropivacaine and $0.5 \%$ bupivacaine epidurally, and concluded that there were no significant differences in the block parameters but ropivacaine was associated with relatively longer duration of postoperative analgesia. ${ }^{18}$

In 2004, Cline et al ${ }^{19}$ compared $0.5 \%$ levobupivacaine and $0.5 \%$ ropivacaine in combination with $1: 200,000$ epinephrine for axillary brachial plexus block, and found that sensory analgesia was significantly longer with levobupivacaine than with ropivacaine, but ropivacaine patients showed a faster recovery of motor function. This was similar to our study findings.

Senard et $\mathrm{al}^{20}$ in 2004 compared the efficacy, dose requirements, side effects and motor block with epidural infusion of $0.1 \%$ levobupivacaine or $0.1 \%$ ropivacaine with added $0.1 \mathrm{mg} /$ hour morphine after major abdominal surgery, and showed no differences in quality of pain relief and hourly consumption of the local anaesthetic mixture between the two groups; however, recovery of unassisted ambulation was quicker with ropivacaine than levobupivacaine $(76 \%$ of patients were able to ambulate on the second postoperative day with ropivacaine versus $48 \%$ with levobupivacaine; $\mathrm{P}$ $<0.05$ ) which correlated with our study.

The interpretation of the finding for ropivacaine causing a less intense motor block and a more rapid recovery of the sensory and motor functions has been the subject of some controversy. Some have argued that this is a specific drug effect of ropivacaine demonstrating an increased separation of the sensory and motor blocking effects by virtue of a lower lipid solubility whereas others claim that the observed differences are merely due to reduced potency of ropivacaine compared with bupivacaine. In our study, we found patients in the ropivacaine group having a similar duration of sensory block, but motor block was less intense and shorter duration with ropivacaine. This finding appears to add weight to the argument for an increased motor/sensory difference with ropivacaine. If the differences in that study were due just to differences in potency, we would expect parallel differences in the motor and sensory components.

\section{CONCLUSIONS}

In the present study, using $0.5 \%$ ropivacaine and $0.5 \%$ levobupivacaine epidurally, levobupivacaine produced a sensory block of similar onset, quality, and duration as ropivacaine but a longer duration of motor block. Further studies are needed to support our results.

\section{REFERENCES}

1. Dolin SJ, Cashman JN, Bland JM. Effectiveness of acute postoperative pain management: I. evidence from published data. Br J Anaesth 2002;89(3):409-23.

2. Liu S, Carpenter RL, Neal JM. Epidural anesthesia and analgesia. Their role in postoperative outcome. Anesthesiology 1995;82(6):1474-506.

3. Wu CL, Fleisher LA. Outcomes research in regional anesthesia and analgesia. Anesth Analg 2000;91(5):123242.

4. Whiteside JB, Wildsmith JA. Developments in local anaesthetic drugs. Br J Anaesth 2001;87(1):27-35.

5. Leone S, Di Cianni S, Casati A, et al. Pharmacology, toxicology, and clinical use of new long acting local anesthetics, ropivacaine and levobupivacaine. Acta Biomed 2008;79(2):92-105.

6. Stienstra R. The place of ropivacaine in anesthesia. Acta Anaesthesiol Belg 2003;54(2):141-8. 
7. Brown DL, Carpenter RL, Thompson GE. Comparison of $0.5 \%$ ropivacaine and $0.5 \%$ bupivacaine for epidural anesthesia in patients undergoing lower-extremity surgery. Anesthesiology 1990;72(4):633-6.

8. Concepcion M, Arthur GR, Steele SM, et al. A new local anesthetic, ropivacaine. Its epidural effects in humans. Anesth Analg 1990;70(1):80-5.

9. Zaric D, Axelsson K, Nydahl PA, et al. Sensory and motor blockade during epidural analgesia with $1 \%, 0.75 \%$, and $0.5 \%$ ropivacaine--a double-blind study. Anesth Analg 1991;72(4):509-15.

10. Bajwa SJ, Kaur J. Clinical profile of levobupivacaine in regional anesthesia: a systematic review. J Anaesthesiol Clin Pharmacol 2013;29(4):530-9.

11. Cox CR, Faccenda KA, Gilhooly C, et al. Extradural S(-)bupivacaine: comparison with racemic RS-bupivacaine. Br JAnaesth 1998;80(3):289-93.

12. Casimiro C, Rodrigo J, Mendiola MA, et al. Levobupivacaine plus fentanyl versus racemic bupivacaine plus fentanyl in epidural anaesthesia for lower limb surgery. Minerva Anestesiol 2008;74(78):381-91.

13. Casati A, Santorsola R, Aldegheri G, et al. Intraoperative epidural anesthesia and postoperative analgesia with levobupivacaine for major orthopedic surgery: a doubleblind, randomized comparison of racemic bupivacaine and ropivacaine. J Clin Anaesth 2003;15(2):126-31.
14. Peduto VA, Baroncini S, Montanini S, et al. A prospective, randomized, double-blind comparison of epidural levobupivacaine $0.5 \%$ with epidural ropivacaine $0.75 \%$ for lower limb procedures. Eur J Anaesthesiol 2003;20(12):979-83.

15. Jung SM, Kang PS, Kwon HU, et al. Comparison of epidural anesthesia with levobupivacaine and ropivacaine for caesarean section. Anesthesiology 2006;105:A1663.

16. Luck JF, Fettes PD, Wildsmith JA. Spinal anaesthesia for elective surgery: a comparison of hyperbaric solutions of racemic bupivacaine, levobupivacaine, and ropivacaine. Br J Anaesth 2008;101(5):705-10.

17. Ingelmo $P$, Frankey $G$, Astuto $M$, et al. Relative analgesic potencies of levobupivacaine and ropivacaine for caudal anaesthesia in children. Anesth Analg 2009;108(3):80513.

18. Chandran S, Hemalatha S, Viswanathan PN. Comparison of $0.75 \%$ ropivacaine and $0.5 \%$ bupivacaine for epidural anaesthesia in lower extremity orthopaedic surgeries. Indian J Anaesth 2014;58(3):336-8.

19. Cline E, Franz D, Polley RD, et al. Analgesia and effectiveness of levobupivacaine compared with ropivacaine in patients undergoing an axillary brachial plexus block. AANA J 2004;72(5):339-45

20. Senard M, Kaba A, Jacquemin MJ, et al. Epidural levobupivacaine $0.1 \%$ or ropivacaine $0.1 \%$ combined with morphine provides comparable analgesia after abdominal surgery. Anesth Analg 2004;98(2):389-94. 